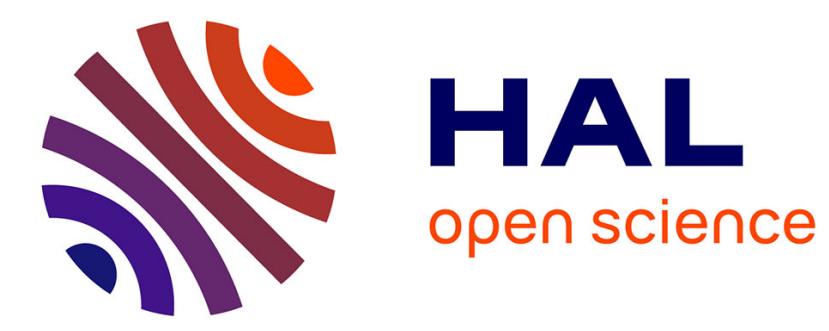

\title{
Pheochromocytoma: A genetic and diagnostic update
}

Leilani B Mercado-Asis, Katherine I Wolf, Ivana Jochmanova, David Taïeb

\section{To cite this version:}

Leilani B Mercado-Asis, Katherine I Wolf, Ivana Jochmanova, David Taïeb. Pheochromocytoma: A genetic and diagnostic update. Endocrine Practice, 2018. hal-01789514

\section{HAL Id: hal-01789514 \\ https://hal.science/hal-01789514}

Submitted on 11 May 2018

HAL is a multi-disciplinary open access archive for the deposit and dissemination of scientific research documents, whether they are published or not. The documents may come from teaching and research institutions in France or abroad, or from public or private research centers.
L'archive ouverte pluridisciplinaire HAL, est destinée au dépôt et à la diffusion de documents scientifiques de niveau recherche, publiés ou non, émanant des établissements d'enseignement et de recherche français ou étrangers, des laboratoires publics ou privés. 


\title{
Pheochromocytoma: A genetic and diagnostic update
}

\author{
Leilani B. Mercado-Asis ${ }^{1}$, Katherine I. Wolf ${ }^{2}$, Ivana Jochmanova ${ }^{2,3}$, David Taïeb ${ }^{4}$
}

\begin{abstract}
${ }^{1}$ Section of Endocrinology and Metabolism, Department of Medicine, Faculty of Medicine \& Surgery, University of Santo Tomas Hospital, Espana, Manila, Philippines 1008; ${ }^{2}$ Section on Medical Neuroendocrinology, Eunice Kennedy Shriver National Institute of Child Health and Human Development, National Institutes of Health, Bethesda, Maryland 20892, USA; ${ }^{3} 1$ st Department of Internal Medicine, Medical Faculty of P. J. Šafárik University in Košice, Trieda

SNP 1, 04011, Košice, Slovakia; ${ }^{4}$ Department of Nuclear Medicine, La Timone University Hospital \& CERIMED \& Inserm UMR1068 Marseille Cancerology Research Center, Institut Paoli-Calmettes, Aix Marseille Univ, Marseille, France
\end{abstract}

\section{Short title:}

Keywords: pheochromocytoma, genetics, catecholamines, metanephrines, radionuclide imaging, neoplastic syndromes, hereditary

\section{Word count: 3648}

Number of figures and tables: Tables: 3, Figures: 3

Correspondence: Prof. Leilani B. Mercado-Asis, MD, PhD, MPH, Section of Endocrinology and Metabolism, Department of Medicine, Faculty of Medicine and Surgery, University of Santo Tomas, Espana, Manila, Philippines. Email: lanibmasis@gmail.com, mobile phone: +639228787349 


\begin{abstract}
Objective: Pheochromocytomas and paragangliomas (PPGLs) are neuroendocrine tumors derived from adrenal or extra-adrenal locations, respectively. Most PPGLs synthesize and secrete catecholamines and their metabolites. A majority of PPGLs are hereditary, and cause unspecific symptoms related to catecholamine excess such as palpitations, uncontrolled hypertension, diaphoresis, headaches, shortness of breath, and anxiety. Upon suspicion of PPGL, specific metabolomic, molecular, biochemical, imaging, and histopathological studies are performed to prove, localize, treat, and monitor disease progression. Recently, improved diagnostic tools allow physicians to accurately diagnose PPGL, even in patients presenting with small (less than $1 \mathrm{~cm}$ ) or biochemically silent tumors, which previously delayed proper detection and treatment.
\end{abstract}

Methods: This review outlines the most updated approach to PPGL patients, and presents a new diagnostic approach for physicians in order to increase earlier tumor identification and accurately assess metastatic behavior.

Conclusion: We presented the most recent advances in genetics, epigenetics, metabolomics, biochemical, and imaging diagnoses of this rare tumor in order to properly assess disease, decide treatment options, and manage follow-up. We also elaborated new therapeutic perspectives in these very rare neoplastic entities. 


\section{Introduction}

Pheochromocytomas and paragangliomas (PPGLs) are chromaffin cell neuroendocrine tumors characterized by catecholamine synthesis, release, and metabolism in the adrenal medulla or extra-adrenal sympathetic or parasympathetic paraganglia, respectively (1). With a prevalence of $0.1-0.6 \%$ in hypertensive adults and an annual general population incidence of 1 per 100,000, clinical suspicion remains the primary indicator for initiating a biochemical workup to confirm a diagnosis of PPGL (2).

Patients most commonly present with recurring episodes of hypertension, palpitations, profuse diaphoresis, and pallor $(3,4)$. Less frequently, PPGL may manifest as nausea, vomiting, flushing, and weight loss. Recently, Pourian et al. established a clinical symptomatology likelihood ratio, which found that only palpitations, headache, and diaphoresis are significant when considering a possible PPGL diagnosis (5). Although the general symptoms remain nonspecific, catecholamine-induced organ damage, particularly to the endocrine, metabolic, and cardiovascular systems should indicate a full diagnostic workup for PPGL.

While improper or delayed PPGL diagnosis has long been associated with the destructive results of a sudden release in catecholamines resulting in adverse cardiovascular events $(6,7)$, Ferreira et al. performed the first prospective study on the extent of cardiac involvement in PPGL 
patients (8). Unlike previous reports detailing the reversal of catecholamine-induced myocarditis following removal of the unsuspected tumor (9), Ferreira discovered persistence of subclinical systolic and diastolic dysfunction in addition to markers for focal and diffuse fibrosis, as well as cardiac abnormalities distinct from the hypertensive control subjects used throughout the study $\{$ Ferreira, 2016 \#11021\}. In the future, early identification of cardiac catecholamine toxicity could be used to predict potentially disastrous cardiovascular events and prevent longterm myocardial alterations (8).

The present review highlights the latest genetic, metabolomic, biochemical, and functional imaging approaches to update the diagnostic algorithm of hereditary and sporadic PPGLs.

\section{Genes involved in PPGL tumorigenesis}

A majority of PPGLs can be ascribed to either germline ( 40\%), or somatic mutations $(\sim 30 \%)(10,11,12)$. Mutations in more than 19 genes involved in tumorigenesis were discovered in PPGLs, of which at least 12 are associated with a syndromic PPGL presentation

(Table 1). PPGL susceptibility genes are divided into two clusters, Cluster 1, pseudohypoxic, and Cluster 2 rich in kinase signaling.

Cluster 1 breaks into Cluster 1a, which contains genes encoding Krebs cycle enzymes mitochondrial succinate dehydrogenase complex (SDHx: SDHA, SDHB, SDHC, SDHD), the SDH complex assembly factor $2(S D H A F 2)$, fumarate hydratase $(F H)$, malate dehydrogenase 2 $(M D H 2)$, and isocitrate dehydrogenase $(I D H)$, and Cluster $1 \mathrm{~b}$ consisted of the von Hippel-Lindau (VHL) tumor suppressor gene, hypoxia-inducible factor $2 \alpha$ (EPAS1/HIF2A), egl-9 family hypoxia inducible factor 2 (EGLN2/PHD1) and factor 1 (EGLN1/PHD2); reviewed in (12). 
Tumors harboring mutations in genes from Cluster 1 are highly vascularized and overexpress vascular endothelial growth factor (VEGF) and VEGF receptors (13), which is a part of the pseudohypoxic signature.

Patients with somatic mutations in EPAS1/HIF2A present with a new syndrome of PPGLs with or without erytrocythosis and/or somatostatinomas (14, 15 ). Novel EGLN1 and EGLN2 mutations were also identified in patients presenting with PPGLs and erythrocytosis without EPAS1/HIF2A mutations (16).

PPGLs associated with the second cluster, are comprised of genes involved in kinase receptor signaling: RET protooncogene, neurofibromin 1 (NF1), transmembrane protein 127 (TMEM127), MYC associated factor X $(M A X)$, kinesin family member 1B (KIF1B), HRas protooncogene (HRAS), and ATRX chromatin remodeler (ATRX). Dysregulation of kinase signaling pathways, such as PI3K/AKT or mTOR, results in the activation of pathways involved in oncogenic processes (reviewed in $(12,17,18)$ ).

Focus has now shifted to try and understand the pathogenesis of PPGL and identify similarities in the metabolic changes between PPGLs with different genetic backgrounds. Data indicates that dysregulation of metabolism in both PPGL clusters are linked through the activation of the hypoxia signaling pathway (17). Tumor hypoxia/pseudohypoxia is supposed to have a direct oncogenic or tumor suppressive effect via regulation of various cellular processes. Hypoxia-inducible factors (HIFs) are the key players in cellular responses to hypoxia and the PHD2 - VHL - HIF2 $\alpha$ pathway is critical for erythropoiesis. Partial disturbances in this pathway are associated with erythrocytosis, while substantial changes are involved in tumorigenesis (16), reviewed in (18). Novel $\operatorname{EPAS1/HIF2A}(14,19)$ and $\operatorname{EGLN1/2}(16,20,21)$ mutations identified 
in PPGLs strongly favor hypoxia signaling as one of the key pathways involved in PPGL development.

The HIF signaling pathway can be triggered by many other oxygen-independent impulses; reviewed in (17). In PPGLs, HIF activation occurs 1) when genes directly involved in regulation of hypoxic responses are mutated (Cluster 1 genes), or 2) when mutations in genes involved in the mTOR and PI3K signaling pathways (Cluster 2 genes) indirectly trigger activation (reviewed in (17)).

Several genes have been implicated in the aggressiveness of PPGLs. Sporadic gene mutations related to chromatin remodeling have been elucidated $(22,23)$. For instance, ATRX gene is involved in telomere maintenance and chromosome integrity (24), as well as in the gene expression and transcriptional repression of non-coding Telomeric Repeat-containing RNA (TERRA) (25). Somatic ATRX mutations were identified in $12.6 \%$ of PPGLs, and these mutations are associated with alternative lengthening of telomeres and more aggressive tumor behavior (22). Mutation of the histone 3.3 encoding gene (H3F3A) was discovered in a patient who presented with recurrent giant cell tumor of the tibia and bilateral pheochromocytomas, and paragangliomas, suggesting that the $H 3 F 3 \mathrm{~A}$ mutation was inherited as a driver event in these tumors (23).

PPGLs display a high rate of inherited gene mutations. New data discovered that there are certain genotype-phenotype correlations, including a high risk of metastatic disease development. Therefore, genetic testing should be considered in all PPGL patients (26). Early identification of an underlying genetic mutation can help predict the course of disease and decide on the best treatment strategy. Clinical and biochemical phenotypes can serve as a tool for routing genetic testing (Table 2). 


\section{Metabolomics and pheochromocytoma}

PPGL susceptibility gene mutations result in the dysregulation of cellular key metabolic pathways and subsequent tumorigenic transformation. A metabolic change in transformed cells promotes increased biosynthesis of macromolecules needed for tumor growth and shifts cell metabolism from oxidative phosphorylation to aerobic glycolysis (27).

Measurements of the Krebs cycle and other metabolites in PPGLs confirmed the role of succinate and fumarate in tumorigenesis (Figure 1) (28-31). At high levels, both succinate and fumarate act as competitive inhibitors of $\alpha-\mathrm{KG}$-dependent dioxygenases, including HIF prolyl hydroxylases (PHDs), needed for HIF- $\alpha$ proteasomal degradation; reviewed in (17). Hence, high

levels of succinate and fumarate lead to the activation of the hypoxia signaling pathway and all metabolic consequences, including activation of protumorigenic mechanisms $(27,32)$.

SDHx mutations in PPGLs result in the accumulation of succinate, increased levels of methionine, glutamine, and myoinositol, as well as decreased levels of fumarate, glutamate, citrate, isocitrate, and several other metabolites (Figures 1 \& 2) (30, 31). A high succinate-tofumarate ratio helps discriminate between PPGLs with and without $S D H x$ mutations $(29,30)$. Moreover, simultaneous measurement of all mentioned metabolites discriminates $S D H \mathrm{x}$ from non-SDHx tumors, with a $100 \%$ sensitivity and specificity. This is important for patients with SDHx-related tumors who present with low catecholamine secretion or biochemically silent disease. $S D H x$ tumors (particularly $S D H B$ ) display more aggressive behavior and have a high metastatic potential (33).

Accumulation of fumarate in $\mathrm{FH}$ - and $\mathrm{MDH} 2$-mutated PPGLs promotes oncogenesis through the succination of proteins, an irreversible covalent bond of fumarate to cysteine 
residues in proteins (34-36). Additionally, succinate/fumarate accumulation results in hypermethylated phenotype in $S D H x$ - and $F H$-mutated tumors due to inhibition of ten-eleventranslocation methylcytosine dioxygenase (TET) $(37,38)$. These findings emphasize the interconnection between the Krebs cycle and epigenomic changes (27).

Decreased levels of Krebs cycle intermediates, specifically citrate, isocitrate, and cisaconitate, detected in SDHx- and $V H L$-related PPGLs are also associated with epigenetic and metabolic changes participating in oncogenic processes. Citrate can switch between metabolic pathways and is also used for synthesis of pyruvate, fatty acids, and sterols. Decreased citrate levels has been linked to the induction of epithelial-to-mesenchymal transition, and thus, cancer cell invasion and metastasis (39).

Metabolomic studies conducted on PPGLs revealed other interesting findings. SDHxmutated tumors displayed a lower activity of SDH enzyme (complex II of electron transport chain), but increased activities of complexes I, III, and IV of the electron transport chain. However, the increased activities of the remaining complexes did not lead to full restoration of normal function (40). High levels of glutamine, the second most abundant nutrient in cancer cells, in SDHx-related PPGLs suggest that glutamine metabolism is involved in the pathogenesis of these tumors (31). The differences in catecholamine synthesis and secretion among PPGLs with different genetic backgrounds can also be explained based on the metabolic changes resulting from particular mutation, specifically by mutation-dependent changes in energy metabolism (40). In PPGLs, ascorbate, a cofactor in the conversion of dopamine to norepinephrine, is accumulated. Levels of ascorbate were found to correlate with concentrations of catecholamines (31). Perhaps interesting, is the finding that ATP production is not impaired in 
SDH deficient PPGLs, implying that Krebs cycle and oxidative phosphorylation function together with aerobic glycolysis in these tumors $(27,31)$.

Based on the available data, PPGLs are very heterogeneous tumors and exhibit diverse metabolic changes and specific metabolic signatures. Further understanding the PPGL metabolism will help us to improve diagnostic and therapeutic methods.

\section{Developments in the Biochemical Evaluation of PPGL}

Upon clinical suspicion of PPGL, a biochemical evaluation using plasma and urinary catecholamines and their O-methylated metabolites, metanephrines should be initiated to confirm diagnosis $(3,33)$. Proper adherence to suggested guidelines is paramount in collecting evidence of inappropriate catecholamine production (41). Despite recent debate, numerous studies have confirmed that lying supine at rest for 20 minutes prior to blood collection prevents false-positive results due to a postural-related stimulus of norepinephrine secretion $(26,42,43)$. Interference is also seen with tricyclic antidepressants, phenoxybenzamine, cigarette smoking, caffeine intake, and consumption of catecholamine-rich foods such as fruits, nuts, cheese, and alcohol $(3,44,45)$. Discontinuing the above medications and substances 24 hours prior to blood draw will help increase the diagnostic sensitivity and limit inappropriate disease exclusion due to false-negative test results.

Eisenhofer et al. recently revealed that an optimized curvilinear model with age-adjusted cut-offs for the upper reference limit of normetanephrine improved diagnostic performance with a significant increase in specificity (93.4\%), and a non-significant loss in sensitivity (93.7\%), compared to the 97.5 percentiles of the reference population, $88.3 \%$ and $93.9 \%$, respectively (43). While positive correlations between metanephrine concentration and age were likewise discovered, the upper reference limits only deviated 30\% across various age groups. However, 
with a single adjustment of the upper reference limit of metanephrine from $0.325 \mathrm{nmol} / \mathrm{L}$ to $0.446 \mathrm{nmol} / \mathrm{L}$, the diagnostic specificity increased from $88.3 \%$ to $96.0 \%$ (43).

The latest reports suggest that age is not the only significant factor requiring reference range adjustment for early and accurate tumor identification. After a unilateral or bilateral adrenalectomy, epinephrine is expected to decrease, which will in turn decrease the plasma concentration of metanephrine (46). Osinga et al. discovered that epinephrine does decrease following adrenalectomies, but norepinephrine increases. Thus, an upward adjustment is required for the reference value of norepinephrine, while a downward adjustment is necessary for the metanephrine reference intervals in order to properly detect recurrent disease and prevent unnecessary exposure to radiation with anatomical or functional imaging (46).

In addition to plasma and urinary catecholamines and metanephrines, 3methoxytyramine, the O-methylated dopamine metabolite, can aid in the identification of exclusively dopamine secreting tumors, which often occur with an asymptomatic clinical presentation (47). Seventy-two percent of patients with $S D H B$ mutations and $67 \%$ of patients with an SDHD mutation had elevated 3-methoxytyramine compared to 39\% for NFI and MEN2, and just $17 \%$ for $V H L$-associated tumors (48). Furthermore, in 2012, Eisenhofer et al. reported that 3-methoxytyramine was also significantly elevated in patients with metastases even in the absence of an $S D H B$ mutation, and also in patients with metastatic disease secondary to adrenal tumors (33). Therefore, along with previously identified metastatic risk factors such as the presence of an $S D H B$ mutation, a tumor diameter greater than $5 \mathrm{~cm}$, and extra-adrenal lesion locations, 3-methoxytyramine is considered a novel biomarker in indicating the likelihood of malignancy (33). 
In most countries, laboratories may be unable to measure plasma and urinary catecholamines, metanephrines, and 3-methoxtyramine. Specialized research centers may be required to perform the most complete and accurate biochemical testing until widespread availability is achieved. Institutional differences in biochemical reference rages and techniques is important to note, indicating that direct laboratory comparisons from various centers should be avoided.

\section{Advances in Functional Imaging}

After PPGL is biochemically proven, anatomical imaging with computed tomography (CT) or magnetic resonance imaging (MRI) is performed. Upon CT or MRI lesion confirmation, the patient's biochemical phenotype and tumor size, as well as metastatic potential, plays a determining role in whether further imaging with functional studies is required $(49,50)$. PPGL patients with a single, epinephrine or metanephrine secreting adrenal mass less than $5 \mathrm{~cm}$, will most likely not benefit from functional imaging, since these tumors are confined to the adrenal gland and present with a small likelihood of metastases (49). However, for lesions greater than 5 $\mathrm{cm}$, secreting norepinephrine or normetanephrine, located extra-adrenally, or associated with a hereditary tumor syndrome such as $S D H B$, the metastatic potential is much higher and functional imaging is necessary to determine the extent of disease $(49,50)$.

PPGLs overexpress somatostatin receptors (SSTRs) (51-54), which has shifted focus to newly developed imaging modalities targeting SSTRs. DOTA peptides, particularly ${ }^{68} \mathrm{Ga}-$ DOTA(0)-Tyr(3)-octreotate $\left({ }^{68} \mathrm{Ga}\right.$-DOTATATE), are quickly emerging as the gold standard of PPGL functional imaging. While ${ }^{18} \mathrm{~F}$-FDOPA PET/CT was previously found to be the most sensitive radiopharmaceutical in the detection of metastatic PPGL (55-57), ${ }^{68}$ Ga-DOTATATE PET/CT showed a significantly superior lesion detection rate over other functional and 
anatomical imaging modalities, as well as demonstrated a 100-fold higher affinity for SSTR2 than the previous first line SSTR scintigraphy ${ }^{111}$ In-DTPA-octreotide (Octreoscan) (58). Tan et al. found that utilizing different radiotracers provides imaging of real disease extension, but this practice is time-consuming, impractical, and not cost-effective, which lead to their recommendation that ${ }^{68} \mathrm{Ga}$-DOTATATE PET/CT become standard of care in determining tumor extent and evaluating metastatic disease (59). Furthermore, avid enhancement on ${ }^{68} \mathrm{Ga}-$ DOTATATE PET/CT could indicate the potential for an additional systemic treatment option with peptide receptor radionuclide therapy $(\operatorname{PRRT})(58,60)$.

While ${ }^{68} \mathrm{Ga}$-DOTATATE PET/CT surpassed ${ }^{18}$ F-FDOPA PET/CT as the functional imaging modality of choice, particularly in sporadic and $S D H B$-related metastatic disease, as well as in head and neck paragangliomas (HNPGLs) (58, 61-63), Darr et al. recently revealed the superiority of ${ }^{18}$ F-FDOPA PET/CT in detecting multifocality/metastases in somatic HIF2A gainof-function mutation patients (64).

In a recent report from Archier et al., ${ }^{68}$ Ga-DOTATATE PET/CT failed to detect an SDHx-related, small pheochromocytoma in the adrenal gland (61), which again brings attention to the high physiological ${ }^{68}$ Ga-DOTATATE uptake by healthy adrenal glands (62). In contrast, ${ }^{18}$ F-FDOPA PET/CT has minimal physiological uptake in the adrenals, and might be beneficial for patients with small, hereditary pheochromocytomas routinely associated with MEN2 and NF1 (61).

While the aforementioned functional imaging modalities, particularly ${ }^{68} \mathrm{Ga}$-DOTATATE PET/CT, are currently unmatched in detection of metastatic disease, their availability is limited (Figure 3). On the other hand, ${ }^{18}$ F-FDG PET/CTs are widely accessible and are the preferred imaging modality for patients with metastatic disease compared to ${ }^{131} \mathrm{I}-\mathrm{MIBG}$, with sensitivities 
of $80 \%$ and $49 \%$, respectively $(26,65-67)$. In SDHx and $V H L$-related lesions, ${ }^{18}$ F-FDG PET/CT showed exceptional metastatic localization $(65,66)$. Until widespread availability of specific radiotracers like ${ }^{68} \mathrm{Ga}$-DOTATATE and ${ }^{18}$ F-FDOPA,${ }^{18} \mathrm{~F}$-FDG PET/CT still offers an inexpensive, high sensitivity option for patients with metastatic disease.

\section{New Therapeutic Perspectives}

\section{Targeted molecular therapies}

Identifying the genetic background and metabolic alterations in PPGL patients can facilitate a better understanding of PPGL tumorigenesis and allow us to search for new, tumor specific therapeutic targets. Inhibition or alteration of certain metabolic processes involved in tumorigenesis is a very promising therapeutic approach (27). Moreover, based on the genotypephenotype correlations and metabolomics profile, a personalized therapy could be designed for each patient.

In the initial stages of tumorigenesis, (pseudo)hypoxia seems to play an important role in PPGL development, resulting in abnormal metabolic activity. Thus, modifying or interrupting signaling pathways involved in hypoxic responses seem to be an attractive treatment target, reviewed in (27). Several compounds targeting the HIF signaling pathway are under evaluation (Table 3). Several years ago, a tyrosine kinase inhibitor targeting the VEGF receptors - sunitinib - was introduced $(68,69)$. However, clinical studies showed contradictory results $(70-72)$. Everolimus, a compound that targets the mTOR pathway, has been used in a limited number of PPGL cases, with unsatisfactory results $(73,74)$. Nonetheless, co-administration of these compounds with other therapeutic agents may show anticancer effects. For example, combined 
treatment with NVP-BEZ235, a dual PI3K/mTORC1/2 inhibitor, and lovastatin, a drug known to reduce ERK signaling, showed a significant additive effect, which supports the use of combination therapies in overcoming compensatory upregulation of other pathways and increasing treatment efficacy (75).

A small molecule inhibitor of HIF-2 $\alpha$ (PT2385) is currently being investigated in a Phase 1 clinical trial for the treatment of advanced or metastatic clear cell renal cell carcinoma (ccRCC). Preclinical data indicates that orally bioavailable PT2385 disrupts HIF-2 $\alpha$ activity in ccRCC and thereby blocks the expression of multiple tumorigenic factors responsible for unrestrained cancer cell growth and proliferation, tumor angiogenesis, and suppression of antitumor immune responses characteristic of ccRCC. (Peloton Therapeutics Inc., Clinical Trial NCT02293980).

Topoisomerase 1 inhibitors have the ability to interfere with mechanisms that maintain DNA integrity during transcription in both quiescent and dividing cells. In vitro studies showed the effectivity of camptothecin, a prototypical topoisomerase 1 inhibitor, in non-dividing PPGL cells. A co-administration of sub-toxic concentrations of 5-azacytidine, a DNA methylation inhibitor, have shown to increase the efficacy of low concentrations of camptothecin (76). Schovanek et al. demonstrated the effectivity of another topoisomerase 1 inhibitor LMP-400 in the preclinical mouse model of metastatic PPGL. LMP-400 was shown to decrease HIF-1 $\alpha$ levels in tumor cells and reduced tumor growth and metastatic potential. Combination therapy with CVD tested in vitro showed synergistic effect of LMP-400 and CVD (77).

Restoring the enzymatic activity of nonfunctioning Krebs cycle enzymes, replenishing depleted substrates for the cycle, or inhibiting activity of overexpressed enzymes represent other 
possible therapeutic schemes. Small-molecule inhibitors of certain proteins or drugs can restore the functionality of mitochondrial enzymes (Table 3), reviewed in $(27,78)$.

Different therapeutic approaches focus on altering glucose and/or glutamine uptake and metabolism, since these compounds serve as a primary source of energy for cancer cells. Metabolism of glucose and glutamine can be altered by inhibition of uptake (inhibitors of glucose or glutamine transporters), or by inhibition of glycolytic enzymes or glutaminolysis (Table 3), reviewed in (27).

Inhibitors of other metabolic pathways, such as lipids and fatty acid synthesis, are also under development (Table 3). Recently, inhibitors of fatty acid synthase were demonstrated to selectively target cancer cells for apoptosis (79).

In PPGLs, DNA methylation is also affected by metabolic changes driven by underlying gene mutations. SDHx- and $F H$ - mutated PPGLs display a hypermethylator phenotype (37), indicating the use of DNA demethylating agents in therapy of some PPGLs (80).

\section{Radionuclide therapy}

Surgical resection remains the best treatment option for PPGL. However, an operative approach is not always viable due to extensive metastatic tumor burden. Therefore, inoperable lesions have been treated with systemic targeted radiotherapies, mainly ${ }^{131} \operatorname{I-MIBG}(81,82)$. Lack of uptake on ${ }^{123}$ I-MIBG scintigraphy excludes many patients from therapy, driving researchers to discover alternative treatment options for non-surgical candidates. SSTR overexpression in PPGL led to their use as therapeutic targets. By attaching radionuclides $\left({ }^{177} \mathrm{Lu}\right.$, ${ }^{90} \mathrm{Y},{ }^{111} \mathrm{In}$ ) via a linker and vector mechanism to a targeting moiety (DOTATATE, DOTANOC, DOTATOC), PRRT has been studied in well-differentiated, advanced neuroendocrine tumors 
(NETs)(83-87). While overall results have varied, the majority of studies report the feasibility, effectiveness, and efficacy of PRRT in NETs $(84,87)$, with increased progression free survival (PFS), as well as patient reported pain relief, symptom regression, and increased quality of life (83). The NETTER-1 Phase III trial compared ${ }^{177}$ Lu-DOTATATE treatment with the cold analog Octreotide LAR, and found that the median PFS was not reached in the ${ }^{177}$ Lu-DOTATATE arm, but was 8.4 months for Octreotide LAR - while maintaining a safety profile unremarkable for significant findings related to hematological, renal, or hepatic parameters (87).

Studies are limited regarding PRRT and PPGL, exclusively. Recently, Pinato et al. revealed an overall radiologic disease control rate of $80 \%$ in a small cohort of $S D H B$-related metastatic PPGL patients treated with ${ }^{177}$ Lu-DOTATATE (85). With only one case of significant toxicity and a median time to progression unreached in their 13 month follow-up timeframe, they concluded that PRRT is a viable, tolerable therapy for PPGL. In 2012, a similar study looked at 4

female $S D H D$-related non-metastatic HNPGL patients undergoing ${ }^{177}$ Lu-DOTATATE treatment, and also reported limited, predictable side effects, with all patients either partially responding or with stable disease (86). Large-scale studies are needed to confirm the data from these limited patient populations, particularly in metastatic sporadic patients without an underlying genetic mutation.

\section{Conclusions}

We present the most recent advances in genetics, epigenetics, metabolomics, biochemical, and imaging diagnoses of this rare tumor in order to properly assess disease, decide treatment options, and manage follow-up. At initial presentation, a complete history and physical examination should be performed, with particular attention paid to possible syndromic features. 
Urinary and/or plasma catecholamine biochemistry should follow, along with 3methoxytyramine where available. Blood samples should be drawn with the patient lying supine for at least 20 minutes prior to extraction. Following elevated biochemistry, the next step is anatomical imaging with CT or MRI. Upon lesion confirmation, functional imaging may be appropriate. ${ }^{68} \mathrm{Ga}$-DOTATATE PET/CT and ${ }^{18} \mathrm{~F}$-FDG PET/CT are the first nuclear scans that should be utilized when metastatic disease is suspected, particularly in $S D H B$-related and HNPGLs. Surgical removal of localized lesions remains the best treatment option for patients with PPGL. When a curative operation is not feasible, targeted molecular therapy or radiotherapy with ${ }^{131}$ I-MIBG or PRRT should be evaluated. The most effective treatment and follow-up plans are developed with a collaborative, multidisciplinary approach to ensure the patient is adequately assessed from the endocrine, cardiology, oncology, and surgical points of view.

\section{Declaration of Interests}

The authors declare that there is no conflict of interest that could be perceived as prejudicing the impartiality of this review.

\section{Funding}

This research was supported, in part, by the Intramural Research Program of the Eunice Kennedy Shriver NICHD, NIH.

\section{Acknowledgement}

The authors are grateful for the technical support of Ms. Jacquelin Marata, and Dr. Alessio Imperiale and Dr. Battini for providing data on metabolomics. 


\section{Author contribution statement}

The authors of this manuscript contributed equally to its creation.

\section{FIGURE LEGENDS}

Figure 1. Metabolic changes and tumorigenesis in PPGL. Schematic representation of mitochondrial genes involved in PHEO development with emphasis to the Krebs cycle enzymes and candidate genes (red) (See Fig.2) and possible areas for therapeutic targets (see Table 3). Dotted lines result from mutations of genes or proteins (red). SDHB has been shown to have the abnormal metabolic characteristics. Abbreviations: $\alpha-\mathrm{KGDH}$, alpha-ketoglutarate dehydrogenase; ACO, aconitase; CoA, coenzyme A; COMT, catechol- $O$-methyl transferase; CS, citrate synthase, c-MYC, MYC proto oncognene; elF-4E, eukaryotic initiation factor 4E; EMT, epithelial-to-mesenchymal transition; ERK, extracellular signal-regulated kinase; FH, fumarate hydroxylase; HIF- $\alpha$, hypoxia-inducible factor alpha; IDH, isocitrate dehydrogenase; MDH2, malate dehydrogenase; mTORC1, mammalian target of rapamycin complex 1; PDH, pyruvate dehydrogenase; PHD, prolyl hydroxylase domain protein; pVHL, von Hippel-Lindau protein; Raptor, regulatory associated protein of mTOR; RAS, rat sarcoma oncogene; RET, rearranged during transfection proto-oncogene; ROS, reactive oxygen species; S6K, S6 kinase; SDH, succinate dehydrogenase; SUCLG, succinyl-CoA synthase; TMEM127, transmembrane protein 127 (partially adapted from $(27,31)$.

Figure 2. Whole tumoral metabolome (A) and three-component OPLS-DA model (B) in SDHx versus sporadic PHEOs. Note that $S D H x$ tumors have higher succinate, taurine and myoinositol metabolic fingerprint. Abbreviations: OPLS-DA, orthogonal partial least square discriminant analysis; GSH, glutathione; Ad; adenine; NAd, nicotinamide-adenine dinucleotide (28) . 
Figure 3. A Comparison of Functional Imaging Modalities

Table 1 Genetic syndromes associated with PPGL development

\begin{tabular}{|c|c|c|c|}
\hline Gene & Locus & Syndrome & Inheritance \\
\hline SDHA & $5 \mathrm{p} 15$ & Paraganglioma syndrome 5 & $\mathrm{n} / \mathrm{a}$ \\
\hline SDHB & $1 \mathrm{p} 36.13$ & Paraganglioma syndrome 4 & $\mathrm{AD}$ \\
\hline SDHC & $1 \mathrm{q} 23.3$ & Paraganglioma syndrome 3 & $\mathrm{AD}$ \\
\hline$S D H D$ & $11 \mathrm{q} 23$ & Paraganglioma syndrome 1 & $\begin{array}{l}\mathrm{AD} \\
\text { paternal }\end{array}$ \\
\hline SDHAF2 & $11 \mathrm{q} 12$ & Paraganglioma syndrome 2 & $\begin{array}{l}\mathrm{AD} \\
\text { paternal }\end{array}$ \\
\hline $\boldsymbol{F H}$ & $11 q 42.1$ & $\mathrm{FH}$ & $\mathrm{n} / \mathrm{a}$ \\
\hline EPAS1/HIF $2 A$ & $2 \mathrm{p} 21$ & $\begin{array}{l}\text { Pacak-Zhuang/Paraganglioma-Polycythemia } \\
\text { syndrome }\end{array}$ & $\mathrm{n} / \mathrm{a}$ \\
\hline$V H L$ & $3 p 25.3$ & Von Hippel-Lindau syndrome & $\mathrm{AD}$ \\
\hline NF1 & $17 q 11.2$ & Neurofibromatosis type 1 & $\mathrm{AD}$ \\
\hline RET & $10 \mathrm{q} 11.21$ & Multiple endocrine neoplasia type 2 & $\mathrm{AD}$ \\
\hline TMEM127 & $2 q 11.2$ & TMEM127 & $\mathrm{AD}$ \\
\hline$M A X$ & $14 q 23.3$ & MAX & $\begin{array}{l}\mathrm{AD}, \\
\text { paternal }\end{array}$ \\
\hline
\end{tabular}

Abbreviations: AD, autosomal dominant; EPAS1/HIF2A, endothelial PAS domain protein 1/hypoxia-inducible factor 2 alpha; $F H$, fumarate hydratase; $M A X$, myc-associated factor X; $N F 1$, neurofibromin; RET, ret proto-oncogene; $S D H A,-B,-C,-D$, succinate dehydrogenase subunits A, B, C, D; SDHAF2; succinate dehydrogenase complex assembly factor 2; TMEM127, transmembrane protein 127; VHL, von Hippel-Lindau gene 
Table 2 Genetic testing based on biochemical and clinical phenotype

\begin{tabular}{|c|c|c|}
\hline Biochemical profile & Clinical presentation & Gene mutation \\
\hline & $\begin{array}{l}\text { Family } \\
\text { history/syndromic } \\
\text { presentation }\end{array}$ & $\begin{array}{l}\text { Test for specific mutation (RET, VHL, } \\
\text { NF1, SDHx, MAX,TMEM127, } \\
\text { EPAS1/HIF } 2 A, E G L N 1 / 2)\end{array}$ \\
\hline Adrenergic & & NF1, RET, MAX, TMEM127 \\
\hline \multirow{4}{*}{$\begin{array}{l}\text { Noradrenergic }(\uparrow \\
\text { NMN) }\end{array}$} & Adrenal & $V H L, S D H B, S D H D, F H$ \\
\hline & Extra-adrenal & $S D H B, S D H D, V H L$ \\
\hline & Metastatic & $S D H B, S D H D, V H L, F H$ \\
\hline & Head and neck & $S D H D, S D H B, S D H C, V H L$ \\
\hline \multirow{4}{*}{$\begin{array}{l}\text { Dopaminergic ( } \uparrow \\
\text { MTY) }\end{array}$} & Adrenal & $S D H B, S D H D, V H L$ \\
\hline & Extra-adrenal & $S D H B, S D H D, V H L$ \\
\hline & Metastatic & $S D H B, S D H D$ \\
\hline & Head and neck & $S D H D, S D H B, S D H C$ \\
\hline Non-secreting & & $S D H B, S D H C, S D H D$ \\
\hline
\end{tabular}

If there is a family history of PPGL and a known PPGL susceptibility mutation, this mutation should be tested first. Patients presenting with a characteristics of PPGL associated syndromes (listed in Table 1), should be tested for genetic mutations associated with those syndromes. Diagnosis of NF1 is usually made based on the clinical presentation of the disease and no genetic testing is needed. In patients without the family history of PPGL, genetic testing is routed based on the biochemical profile and tumor presentation (localization). For some of the genetic mutations, biochemical profile and tumor presentation are not yet known $(1,27,88-90)$.

Abbreviations: $E G L N 1 / 2$, egl-9 family hypoxia inducible factor 1/2; EPAS1/HIF2A, endothelial PAS domain protein 1/hypoxia-inducible factor 2 alpha; $F H$, fumarate hydratase; $M A X$, mycassociated factor X; MN, metanephrine; MTY, 3-methoxytyramine; NMN, normetanephrine; $N F 1$, neurofibromin; RET, ret proto-oncogene; $S D H x$, succinate dehydrogenase subunits; $S D H B$, 
$C, D$, succinate dehydrogenase subunits B, C, D; TMEM127, transmembrane protein 127; VHL, von Hippel-Lindau gene

Table 3 Potential Molecular/Metabolic Therapeutic Targets in Pheochromocytoma

\begin{tabular}{|c|c|c|}
\hline Therapeutic target & Treatment effects & Examples of agents \\
\hline \multicolumn{3}{|l|}{ HIF signaling } \\
\hline HIF- $\alpha$ mRNA/protein expression & $\begin{array}{l}\text { Inhibition of HIF- } \alpha \text { mRNA or } \\
\text { protein expression resulting in } \\
\text { decreased HIF- } \alpha \text { accumulation and } \\
\text { activation }\end{array}$ & $\begin{array}{l}\text { Wortmannin, LY94002, GFC-0941, PI-103, } \\
\text { Rapamycin, PP242, Aminoflavone, } \\
\text { Glyceollins, Topotecan, EZN-2968, 2ME2, } \\
\text { ENMD-1198, Geldanamycin and analogues, } \\
\text { Vorinostat, YC-1, PX-478, PX-12, cardiac } \\
\text { glycosides, FM19G11, HIF-2 } \alpha \text { translational } \\
\text { inhibitors }\end{array}$ \\
\hline HIF- $\alpha$ dimerization & $\begin{array}{l}\text { Inhibition of } \mathrm{HIF}-\alpha / \mathrm{HIF}-1 \beta \\
\text { dimerization }\end{array}$ & Acriflavine, PT2385 \\
\hline HIF binding to DNA & $\begin{array}{l}\text { Inhibition of HIF dimers binding to } \\
\text { DNA }\end{array}$ & Echinomycin, polyamides \\
\hline HIF transcriptional activity & $\begin{array}{l}\text { Inhibition of transcription of HIF } \\
\text { target genes }\end{array}$ & $\begin{array}{l}\text { Chetomin, Bortezomib, Amphotericin B, } \\
\text { Triptolide, AJM290, AW464 }\end{array}$ \\
\hline Hypoxia & Apoptosis of hypoxic cell & $\begin{array}{l}\text { Hypoxia activated prodrugs: TH-302, EO9, } \\
\text { AQ4N, PR-104, Tirapazamine, SN30000, } \\
\text { TH-4000 }\end{array}$ \\
\hline Angiogenesis & VEGF, VEGFR inhibition & $\begin{array}{l}\text { Sunitinib, Sorafenib, Pazopanib, } \\
\text { Bevacizumab }\end{array}$ \\
\hline \multicolumn{3}{|l|}{ Glycolysis } \\
\hline Glucose uptake & Inhibition of glucose transport & $\begin{array}{l}\text { GLUTs inhibitors: Flavonoids (phloretin, } \\
\text { silybin), STF-31, WZB117, ritonavir }\end{array}$ \\
\hline HK $1 / 2$ & Inhibition & $\begin{array}{l}\text { 3-Bromopyruvate } 2 \text {-deoxyglucose, } \\
\text { Lonidamine }\end{array}$ \\
\hline PDK1 & Inhibition (to allow activity of PDH) & dichloroacetate \\
\hline PFKB3 & Inhibition & $3 \mathrm{PO}$ \\
\hline LDHA & Inhibition & $\begin{array}{l}\text { shRNA, Gossypol/AT-101 and Derivates, } \\
\text { Galloflavin }\end{array}$ \\
\hline PKM2 & Induction of apoptosis & $\begin{array}{l}\text { Somatostatin and its derivatives, TLN- } \\
\text { 232/CAP-232 }\end{array}$ \\
\hline MCTs & Inhibition of lactate transport & $\begin{array}{l}\text { AZD3965 MCT1/2 Specific Inhibitors, } \\
\text { CHC, phenylpyruvate, bioflavonoids }\end{array}$ \\
\hline
\end{tabular}




\begin{tabular}{|c|c|c|}
\hline Glutamine uptake & Glutamine transporters inhibition & BCH, GPNA, benzylserine \\
\hline glutaminase & Inhibition & BPTES/CB-839, Compound 968 \\
\hline GOT2/GPT2 & Inhibition & Aminooxyacetate \\
\hline GDH1 & Inhibition & Purpurin/R162, EGCG \\
\hline \multicolumn{3}{|c|}{ Fatty Acid and Lipid Synthesis } \\
\hline ACLY & Inhibition & SB-204990 \\
\hline Acyl-CoA synthetase & Inhibition & \\
\hline Acetyl-CoA carboxylase & $\begin{array}{l}\text { Inhibition, induction of } \\
\text { apoptosis/autophagy }\end{array}$ & Soraphen A \\
\hline Fatty acid synthase & Inhibition, induction of apoptosis & Cerulenin, C75, flavonoids \\
\hline Choline kinase & Inhibition & MN58b \\
\hline Phospholipid metabolism & Inhibition & metformin \\
\hline \multicolumn{3}{|c|}{ Dysfunctional Krebs Cycle Enzymes And Metabolites } \\
\hline IDH1/2 & $\begin{array}{l}\text { Inhibition of IDH mutants, } \\
\text { inhibition of } 2 \mathrm{HG} \text { production }\end{array}$ & Mutant IDH inhibitors \\
\hline $\begin{array}{l}\alpha \text {-ketoglutarate dependent } \\
\text { dioxygenases }\end{array}$ & Restoring the function & $\alpha$-ketoglutarate analogs \\
\hline Low citrate & $\begin{array}{l}\text { Increase in citrate levels, inhibition } \\
\text { of PFK, arrest of glycolysis, } \\
\text { induction of apoptosis }\end{array}$ & Citrate \\
\hline \multicolumn{3}{|l|}{ Other } \\
\hline DNA methylation & Inhibition of methylation & DNA demethylating agents: decitabine \\
\hline AMPK & Activation & $\begin{array}{l}\text { Biguanides, thiazolidinediones, } \\
\text { bevacizumab, erlotinib }\end{array}$ \\
\hline LAT1 & Inhibition of amino acid transport & $\begin{array}{l}\text { 2-aminocyclo (2.2.1)-heptane 2-carboxylic } \\
\text { acid }\end{array}$ \\
\hline SIRT1 & $\begin{array}{l}\text { Stimulation of SIRT1-dependent } \\
\text { deacetylation PGC1 } \alpha\end{array}$ & Resveratrol \\
\hline ROS & $\begin{array}{l}\text { Neutralizing ROS by antioxidants to } \\
\text { reduce HIF- } \alpha \text { activation }\end{array}$ & $\mathrm{N}$-acetylcysteine, vitamin $\mathrm{C}$ \\
\hline ROS & Induction of ROS overproduction & $\begin{array}{l}\text { Menandione, Gadolinium texaphyrin, } \beta \text { - } \\
\text { lapachone }\end{array}$ \\
\hline Antioxidant systems (GSH) & $\begin{array}{l}\text { Inhibition to achieve ROS } \\
\text { accumulation }\end{array}$ & $\begin{array}{l}\text { Buthionine sulphoximine, Isothiocyanates, } \\
\text { Mangafodipir }\end{array}$ \\
\hline
\end{tabular}

Adapted from (27)

Abbreviations: 2HG, 2-hydroxyglutarate; 3PO, 3-(3-pyridinyl)-1-(4-pyridinyl)-2-propen-1-on; Acetyl-CoA, acetyl coenzyme A; ACLY, ATP citrate lyase; AMPK, AMP-activated protein kinase; ATP, adenosine triphosphate; $\mathrm{BCH}$, 2- aminobicyclo(2,2,1)-heptane-2-carboxylic acid; BPTES, bis-2-[5-phenylacetamido-1, 2, 4-thiadiazol-2-yl] ethyl sulfide; CHC, $\alpha$-cyano-4hydroxycinnamate; CoA, coenzyme A; DNA, deoxyribonucleic acid; EGCG, epigallocatechin gallate; GDH1, glutamate dehydrogenase 1; GLUT, glucose transporter; GOT2, glutamate oxaloacetate transaminase 2; GPNA, $\gamma$-L-glutamyl-p-nitroanilide; GPT2, glutamate pyruvate transaminase 2; HIF, hypoxia-inducible factor; HK, hexokinase; IDH, isocitrate dehydrogenase; LAT1, L-type amino acid transporter 1; LDHA, lactate dehydrogenase A; LY94002, 2Morpholin-4-yl-8-phenylchromen-4-one; MCT, monocarboxylase transporter; PDH, pyruvate dehydrogenase; PDK, pyruvate dehydrogenase kinase; PFK, phosphofructokinase; mRNA, messenger RNA; PGC1 $\alpha$, peroxisome proliferator-activated receptor- $\gamma$ co-activator $1 \alpha$; PHD, prolyl hydroxylase domain-containing protein; PKM2, pyruvate kinase, isoenzyme 2; ROS, reactive oxygen species; SDH, succinate dehydrogenase; shRNA, short hairpin RNA; SIRT1, 
sirtuin 1; VEGF, vascular endothelial growth factor; VEGFR, vascular endothelial growth factor receptor.

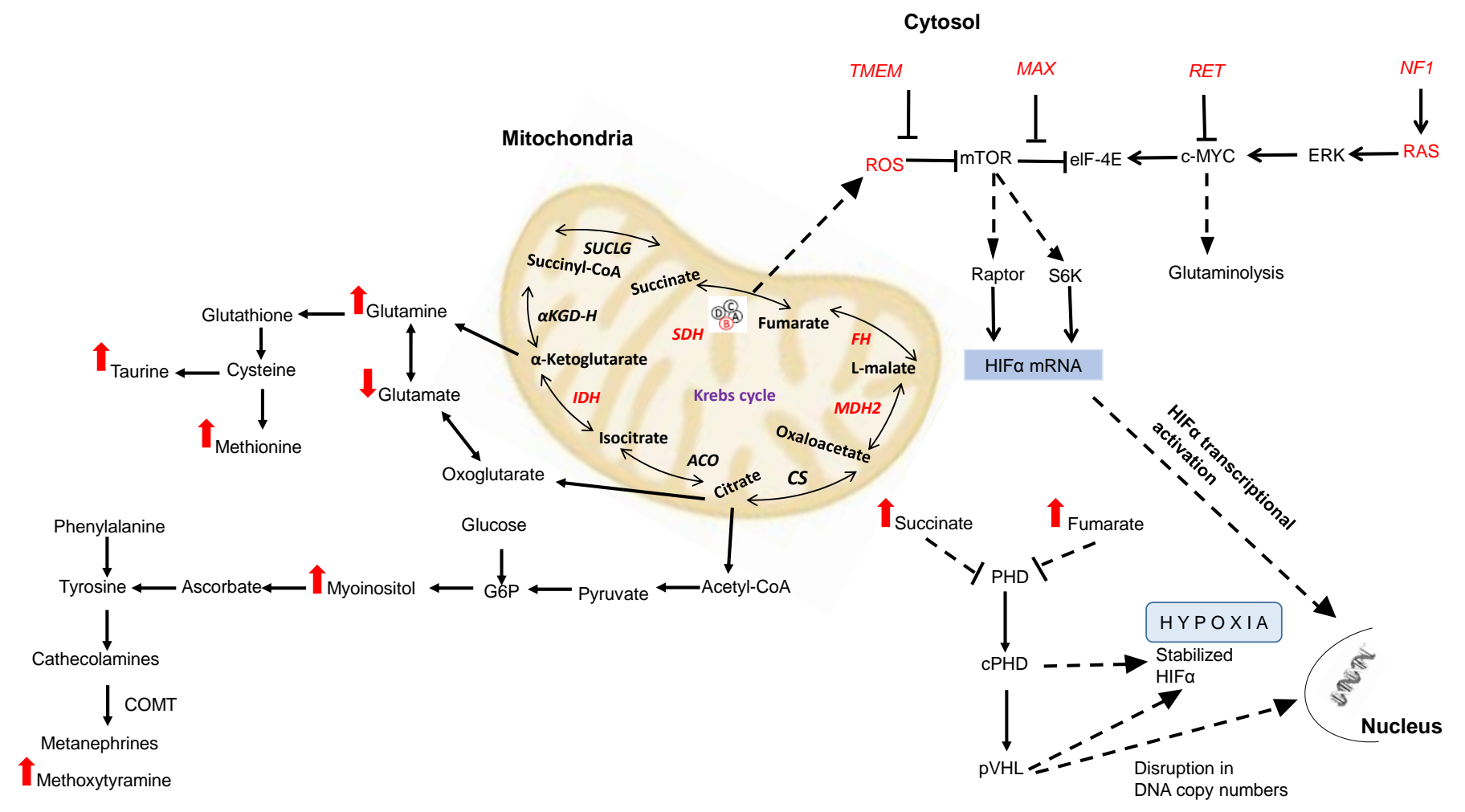

Figure 1 


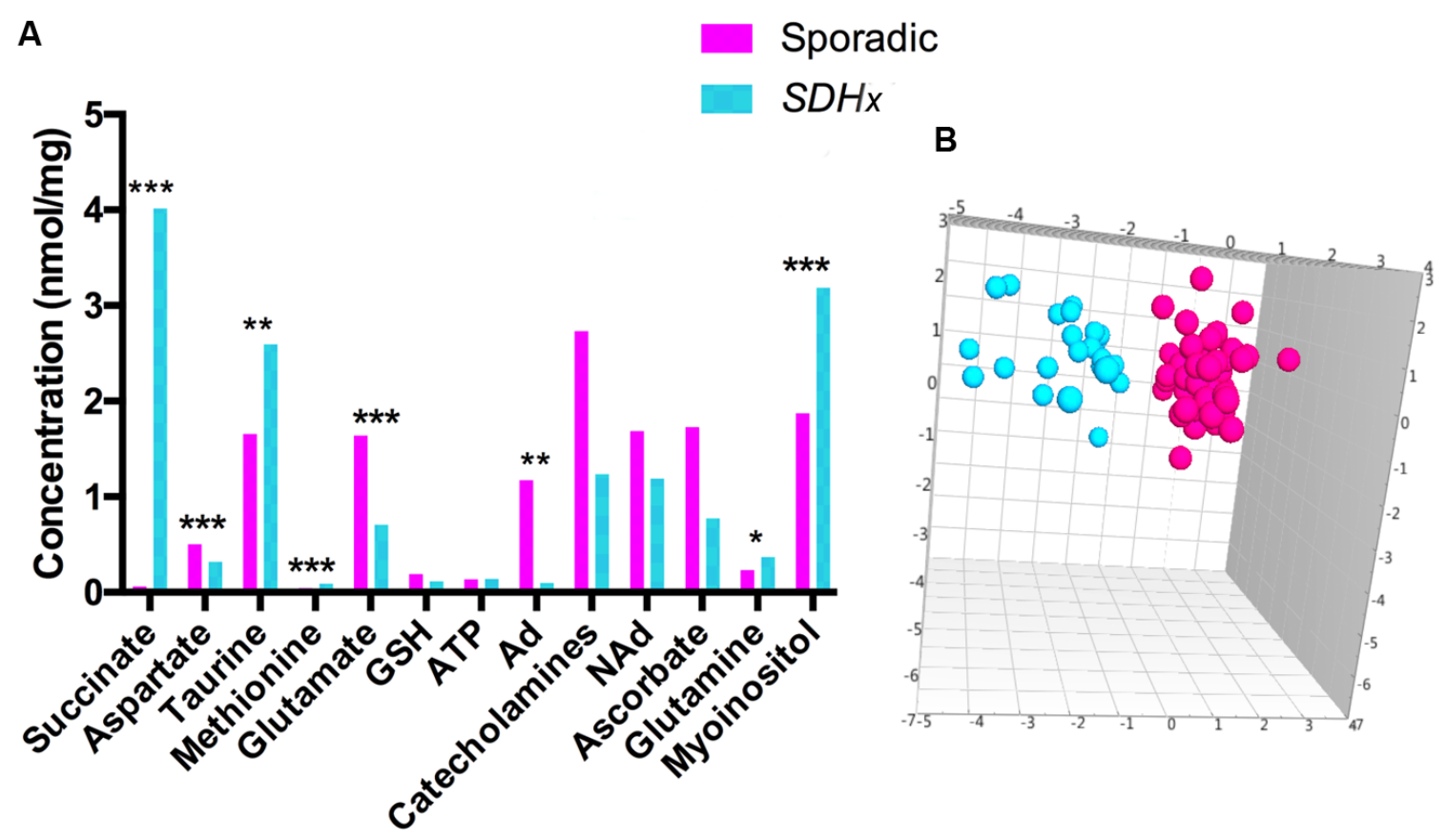

Figure 2 

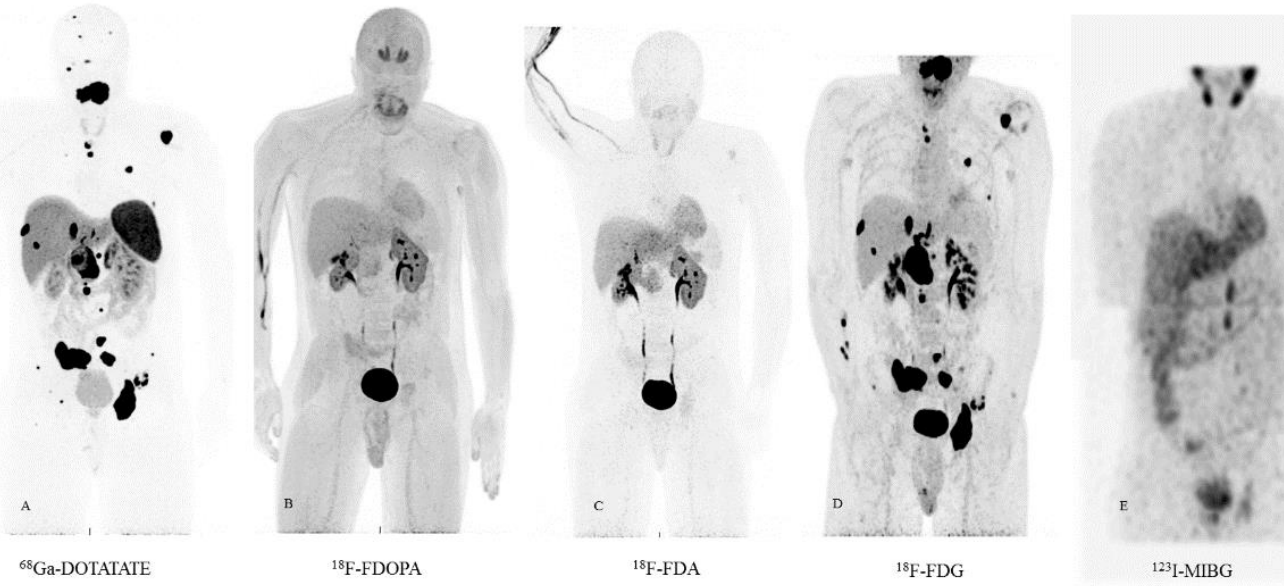

Figure 3 


\section{References}

1. Martucci VL, Pacak K. Pheochromocytoma and paraganglioma: diagnosis, genetics, management, and treatment. Current problems in cancer. 2014;38:7-41.

2. Kolackov K, Tupikowski K, Bednarek-Tupikowska G. Genetic aspects of pheochromocytoma. Advances in clinical and experimental medicine : official organ Wroclaw Medical University. 2012;21:821-829.

3. Lenders JW, Eisenhofer G, Mannelli M, Pacak K. Phaeochromocytoma. Lancet. 2005;366:665-675.

4. Manger WM. The protean manifestations of pheochromocytoma. Hormone and metabolic research $=$ Hormon- und Stoffwechselforschung $=$ Hormones et metabolisme . 2009;41:658-663.

5. Pourian M, Mostafazadeh DB, Soltani A. Does this patient have pheochromocytoma? A systematic review of clinical signs and symptoms. Journal of diabetes and metabolic disorders. 2015;15:11.

6. Otusanya O, Goraya H, Iyer P, Landi K, Tibb A, Msaouel P. A vicious cycle of acute catecholamine cardiomyopathy and circulatory collapse secondary to pheochromocytoma. Oxford medical case reports. 2015;2015:343-345.

7. Zelinka T, Petrak O, Turkova H, et al. High incidence of cardiovascular complications in pheochromocytoma. Hormone and metabolic research $=$ Hormon- und

Stoffwechselforschung = Hormones et metabolisme. 2012;44:379-384.

8. Ferreira VM, Marcelino M, Piechnik SK, et al. Pheochromocytoma Is Characterized by Catecholamine-Mediated Myocarditis, Focal and Diffuse Myocardial Fibrosis, and Myocardial Dysfunction. Journal of the American College of Cardiology. 2016;67:2364-2374.

9. de Miguel V, Arias A, Paissan A, et al. Catecholamine-induced myocarditis in pheochromocytoma. Circulation. 2014;129:1348-1349.

10. Neumann HP, Bausch B, McWhinney SR, et al. Germ-line mutations in nonsyndromic pheochromocytoma. The New England journal of medicine. 2002;346:1459-1466.

11. Gimenez-Roqueplo AP, Dahia PL, Robledo M. An Update on the Genetics of Paraganglioma, Pheochromocytoma, and Associated Hereditary Syndromes. Hormone and metabolic research = Hormon- und Stoffwechselforschung = Hormones et metabolisme 2012. 12. Burnichon N, Buffet A, Gimenez-Roqueplo AP. Pheochromocytoma and paraganglioma: molecular testing and personalized medicine. Curr Opin Oncol. 2016;28:510.

13. Favier J, Igaz P, Burnichon N, et al. Rationale for anti-angiogenic therapy in pheochromocytoma and paraganglioma. Endocrine pathology. 2012;23:34-42.

14. Zhuang Z, Yang C, Lorenzo F, et al. Somatic HIF2A gain-of-function mutations in paraganglioma with polycythemia. The New England journal of medicine. 2012;367:922930.

15. Pacak K, Jochmanova I, Prodanov T, et al. New syndrome of paraganglioma and somatostatinoma associated with polycythemia. Journal of clinical oncology : official journal of the American Society of Clinical Oncology. 2013.

16. Yang C, Zhuang Z, Fliedner SM, et al. Germ-line PHD1 and PHD2 mutations detected in patients with pheochromocytoma/paraganglioma-polycythemia. J Mol Med (Berl).

2015;93:93-104. 
17. Jochmanova I, Yang C, Zhuang Z, Pacak K. Hypoxia-inducible factor signaling in pheochromocytoma: turning the rudder in the right direction. Journal of the National Cancer Institute. 2013;105:1270-1283.

18. Pillai S, Gopalan V, Smith RA, Lam AK. Updates on the genetics and the clinical impacts on phaeochromocytoma and paraganglioma in the new era. Critical reviews in oncology/hematology. 2016;100:190-208.

19. Lorenzo FR, Yang C, Ng Tang Fui M, et al. A novel EPAS1/HIF2A germline mutation in a congenital polycythemia with paraganglioma. J Mol Med (Berl). 2013;91:507-512.

20. Ladroue C, Carcenac R, Leporrier M, et al. PHD2 mutation and congenital erythrocytosis with paraganglioma. The New England journal of medicine. 2008;359:26852692.

21. Welander J, Andreasson A, Juhlin CC, et al. Rare germline mutations identified by targeted next-generation sequencing of susceptibility genes in pheochromocytoma and paraganglioma. J Clin Endocrinol Metab. 2014;99:E1352-1360.

22. Fishbein L, Khare S, Wubbenhorst B, et al. Whole-exome sequencing identifies somatic ATRX mutations in pheochromocytomas and paragangliomas. Nature communications. 2015;6:6140.

23. Toledo RA, Qin Y, Cheng ZM, et al. Recurrent Mutations of Chromatin-Remodeling Genes and Kinase Receptors in Pheochromocytomas and Paragangliomas. Clinical cancer research : an official journal of the American Association for Cancer Research. 2016;22:23012310.

24. Ratnakumar K, Bernstein E. ATRX: the case of a peculiar chromatin remodeler. Epigenetics. 2013;8:3-9.

25. Lovejoy CA, Li W, Reisenweber S, et al. Loss of ATRX, genome instability, and an altered DNA damage response are hallmarks of the alternative lengthening of telomeres pathway. PLoS Genet. 2012;8:e1002772.

26. Lenders JW, Duh QY, Eisenhofer G, et al. Pheochromocytoma and paraganglioma: an endocrine society clinical practice guideline. J Clin Endocrinol Metab. 2014;99:1915-1942.

27. Jochmanova I, Pacak K. Pheochromoctyoma: The First Metabolic Endocrine Cancer. Clinical Cancer Research. 2016;22.

28. Imperiale A, Elbayed K, Moussallieh FM, et al. Metabolomic profile of the adrenal gland: from physiology to pathological conditions. Endocrine-related cancer. 2013;20:705716.

29. Lendvai N, Pawlosky R, Bullova P, et al. Succinate-to-fumarate ratio as a new metabolic marker to detect the presence of SDHB/D-related paraganglioma: initial experimental and ex vivo findings. Endocrinology. 2014;155:27-32.

30. Richter S, Peitzsch M, Rapizzi E, et al. Krebs cycle metabolite profiling for identification and stratification of pheochromocytomas/paragangliomas due to succinate dehydrogenase deficiency. J Clin Endocrinol Metab. 2014;99:3903-3911.

31. Imperiale A, Moussallieh FM, Roche P, et al. Metabolome profiling by HRMAS NMR spectroscopy of pheochromocytomas and paragangliomas detects SDH deficiency: clinical and pathophysiological implications. Neoplasia. 2015;17:55-65.

32. Semenza GL. HIF-1 mediates metabolic responses to intratumoral hypoxia and oncogenic mutations. J Clin Invest. 2013;123:3664-3671.

33. Eisenhofer G, Lenders JW, Siegert G, et al. Plasma methoxytyramine: a novel biomarker of metastatic pheochromocytoma and paraganglioma in relation to established 
risk factors of tumour size, location and SDHB mutation status. Eur J Cancer. 2012;48:17391749.

34. Yang M, Ternette N, Su H, et al. The Succinated Proteome of FH-Mutant Tumours. Metabolites. 2014;4:640-654.

35. Merkley ED, Metz TO, Smith RD, Baynes JW, Frizzell N. The succinated proteome. Mass Spectrom Rev. 2014;33:98-109.

36. Zheng L, Cardaci S, Jerby L, et al. Fumarate induces redox-dependent senescence by modifying glutathione metabolism. Nature communications. 2015;6:6001.

37. Letouze E, Martinelli C, Loriot C, et al. SDH mutations establish a hypermethylator phenotype in paraganglioma. Cancer cell. 2013;23:739-752.

38. Castro-Vega LJ, Buffet A, De Cubas AA, et al. Germline mutations in FH confer predisposition to malignant pheochromocytomas and paragangliomas. Human molecular genetics. 2014.

39. Kruspig B, Zhivotovsky B, Gogvadze V. Mitochondrial substrates in cancer: drivers or passengers? Mitochondrion. 2014;19 Pt A:8-19.

40. Rao JU, Engelke UF, Rodenburg RJ, et al. Genotype-specific abnormalities in mitochondrial function associate with distinct profiles of energy metabolism and catecholamine content in pheochromocytoma and paraganglioma. Clinical cancer research : an official journal of the American Association for Cancer Research. 2013;19:3787-3795.

41. Pacak K, Eisenhofer G. An assessment of biochemical tests for the diagnosis of pheochromocytoma. Nature clinical practice Endocrinology \& metabolism. 2007;3:744-745.

42. Darr R, Pamporaki C, Peitzsch M, et al. Biochemical diagnosis of phaeochromocytoma using plasma-free normetanephrine, metanephrine and methoxytyramine: importance of supine sampling under fasting conditions. Clinical endocrinology. 2014;80:478-486.

43. Eisenhofer G, Lattke P, Herberg M, et al. Reference intervals for plasma free metanephrines with an age adjustment for normetanephrine for optimized laboratory testing of phaeochromocytoma. Annals of clinical biochemistry. 2013;50:62-69.

44. Neary NM, King KS, Pacak K. Drugs and pheochromocytoma--don't be fooled by every elevated metanephrine. The New England journal of medicine. 2011;364:2268-2270. 45. Eisenhofer G, Goldstein DS, Walther MM, et al. Biochemical diagnosis of pheochromocytoma: how to distinguish true- from false-positive test results. J Clin Endocrinol Metab. 2003;88:2656-2666.

46. Osinga TE, van den Eijnden MH, Kema IP, et al. Unilateral and bilateral adrenalectomy for pheochromocytoma requires adjustment of urinary and plasma metanephrine reference ranges. J Clin Endocrinol Metab. 2013;98:1076-1083.

47. Eisenhofer G, Goldstein DS, Sullivan P, et al. Biochemical and clinical manifestations of dopamine-producing paragangliomas: utility of plasma methoxytyramine. J Clin Endocrinol Metab. 2005;90:2086-2075.

48. Eisenhofer G, Lenders JW, Timmers H, et al. Measurements of plasma methoxytyramine, normetanephrine, and metanephrine as discriminators of different hereditary forms of pheochromocytoma. Clinical chemistry. 2011;57:411-420. 49. Roman-Gonzalez A, Jimenez Vasquez P, Mayer Hyde S, Jessop AC, Jimenez C. Management of Locally Advanced and Metastatic Pheochromocytoma and Paraganglioma. In: Kebebew E, ed. Management of Adrenal Masses in Children and Adults: Springer International Publishing, 2017: 277-300. 
50. Kaji P, Carrasquillo JA, Linehan WM, et al. The role of 6-[18F]fluorodopamine positron emission tomography in the localization of adrenal pheochromocytoma associated with von Hippel-Lindau syndrome. European journal of endocrinology / European Federation of Endocrine Societies. 2007;156:483-487.

51. Krenning EP, Kwekkeboom DJ, Pawels S, Kvols LK, Reubi JC. Somatostatin receptor scintigraphy. In: LM F, ed. Nuclear Medicine Annual 1995. New York: Raven Press, 1995: 242-244.

52. de Herder WW, Kwekkeboom DJ, Feelders RA, et al. Somatostatin receptor imaging for neuroendocrine tumors. Pituitary. 2006;9:243-248.

53. Saveanu A, Muresan M, De Micco C, et al. Expression of somatostatin receptors, dopamine $\mathrm{D}(2)$ receptors, noradrenaline transporters, and vesicular monoamine transporters in 52 pheochromocytomas and paragangliomas. Endocrine-related cancer. 2011;18:287-300.

54. Hofman MS, Kong G, Neels OC, Eu P, Hong E, Hicks RJ. High management impact of Ga-68 DOTATATE (GaTate) PET/CT for imaging neuroendocrine and other somatostatin expressing tumours. J Med Imaging Radiat Oncol. 2012;56:40-47.

55. Taieb D, Tessonnier L, Sebag F, et al. The role of 18F-FDOPA and 18F-FDG-PET in the management of malignant and multifocal phaeochromocytomas. Clinical endocrinology. 2008;69:580-586.

56. Gabriel S, Blanchet EM, Sebag F, et al. Functional characterization of nonmetastatic paraganglioma and pheochromocytoma by (18) F-FDOPA PET: focus on missed lesions. Clinical endocrinology. 2013;79:170-177.

57. Imani F, Agopian VG, Auerbach MS, et al. 18F-FDOPA PET and PET/CT accurately localize pheochromocytomas. Journal of nuclear medicine : official publication, Society of Nuclear Medicine. 2009;50:513-519.

58. Janssen I, Blanchet EM, Adams K, et al. Superiority of [68Ga]-DOTATATE PET/CT to Other Functional Imaging Modalities in the Localization of SDHB-Associated Metastatic Pheochromocytoma and Paraganglioma. Clinical cancer research : an official journal of the American Association for Cancer Research. 2015;21:3888-3895.

59. Tan TH, Hussein Z, Saad FF, Shuaib IL. Diagnostic Performance of (68)GaDOTATATE PET/CT, (18)F-FDG PET/CT and (131)I-MIBG Scintigraphy in Mapping Metastatic Pheochromocytoma and Paraganglioma. Nucl Med Mol Imaging. 2015;49:143151.

60. Maurice JB, Troke R, Win Z, et al. A comparison of the performance of (6)(8)GaDOTATATE PET/CT and (1)(2)(3)I-MIBG SPECT in the diagnosis and follow-up of phaeochromocytoma and paraganglioma. European journal of nuclear medicine and molecular imaging. 2012;39:1266-1270.

61. Archier A, Varoquaux A, Garrigue P, et al. Prospective comparison of (68)GaDOTATATE and (18)F-FDOPA PET/CT in patients with various pheochromocytomas and paragangliomas with emphasis on sporadic cases. European journal of nuclear medicine and molecular imaging. 2016;43:1248-1257.

62. Kroiss A, Putzer D, Frech A, et al. A retrospective comparison between 68Ga-DOTATOC PET/CT and 18F-DOPA PET/CT in patients with extra-adrenal paraganglioma. European journal of nuclear medicine and molecular imaging . 2013;40:1800-1808.

63. Janssen I, Chen CC, Millo CM, et al. PET/CT comparing (68)Ga-DOTATATE and other radiopharmaceuticals and in comparison with CT/MRI for the localization of sporadic 
metastatic pheochromocytoma and paraganglioma. European journal of nuclear medicine and molecular imaging. 2016;43:1784-1791.

64. Darr R, Nambuba J, Del Rivero J, et al. Novel insights into the polycythemiaparaganglioma-somatostatinoma syndrome. Endocrine-related cancer. 2016.

65. Timmers HJ, Chen CC, Carrasquillo JA, et al. Staging and Functional Characterization of Pheochromocytoma and Paraganglioma by 18F-Fluorodeoxyglucose (18F-FDG) Positron Emission Tomography. Journal of the National Cancer Institute. 2012;104:700-708. 66. Taieb D, Timmers HJ, Shulkin BL, Pacak K. Renaissance of (18)F-FDG positron emission tomography in the imaging of pheochromocytoma/paraganglioma. J Clin Endocrinol Metab. 2014;99:2337-2339.

67. Taieb D, Timmers HJ, Hindie E, et al. EANM 2012 guidelines for radionuclide imaging of phaeochromocytoma and paraganglioma. European journal of nuclear medicine and molecular imaging. 2012;39:1977-1995.

68. Aita Y, Ishii KA, Saito Y, et al. Sunitinib inhibits catecholamine synthesis and secretion in pheochromocytoma tumor cells by blocking VEGF receptor 2 via PLC-gammarelated pathways. American journal of physiology Endocrinology and metabolism. 2012;303:E1006-1014.

69. Saito Y, Tanaka Y, Aita Y, et al. Sunitinib induces apoptosis in pheochromocytoma tumor cells by inhibiting VEGFR2/Akt/mTOR/S6K1 pathways through modulation of Bcl-2 and BAD. American journal of physiology Endocrinology and metabolism. 2012;302:E615625 .

70. Joshua AM, Ezzat S, Asa SL, et al. Rationale and evidence for sunitinib in the treatment of malignant paraganglioma/pheochromocytoma. J Clin Endocrinol Metab. 2009;94:5-9.

71. Ayala-Ramirez M, Chougnet CN, Habra MA, et al. Treatment with sunitinib for patients with progressive metastatic pheochromocytomas and sympathetic paragangliomas. J Clin Endocrinol Metab. 2012;97:4040-4050.

72. Jimenez C, Cabanillas ME, Santarpia L, et al. Use of the tyrosine kinase inhibitor sunitinib in a patient with von Hippel-Lindau disease: targeting angiogenic factors in pheochromocytoma and other von Hippel-Lindau disease-related tumors. J Clin Endocrinol Metab. 2009;94:386-391.

73. Oh DY, Kim TW, Park YS, et al. Phase 2 study of everolimus monotherapy in patients with nonfunctioning neuroendocrine tumors or pheochromocytomas/paragangliomas. Cancer. 2012;118:6162-6170.

74. Druce MR, Kaltsas GA, Fraenkel M, Gross DJ, Grossman AB. Novel and evolving therapies in the treatment of malignant phaeochromocytoma: experience with the mTOR inhibitor everolimus (RAD001). Hormone and metabolic research = Hormon- und Stoffwechselforschung = Hormones et metabolisme. 2009;41:697-702.

75. Nolting S, Garcia E, Alusi G, et al. Combined blockade of signalling pathways shows marked anti-tumour potential in phaeochromocytoma cell lines. J Mol Endocrinol. 2012;49:79-96.

76. Powers JF, Korgaonkar PG, Fliedner S, et al. Cytocidal activities of topoisomerase 1 inhibitors and 5-azacytidine against pheochromocytoma/paraganglioma cells in primary human tumor cultures and mouse cell lines. PloS one. 2014;9:e87807. 
77. Schovanek J, Bullova P, Tayem Y, et al. Inhibitory Effect of the Noncamptothecin Topoisomerase I Inhibitor LMP-400 on Female Mice Models and Human Pheochromocytoma Cells. Endocrinology. 2015;156:4094-4104.

78. Jochmanova I, Zhuang Z, Pacak K. Pheochromocytoma: Gasping for Air. Hormones \& cancer. 2015;6:191-205.

79. Mullen GE, Yet L. Progress in the development of fatty acid synthase inhibitors as anticancer targets. Bioorg Med Chem Lett. 2015;25:4363-4369.

80. Favier J, Amar L, Gimenez-Roqueplo AP. Paraganglioma and phaeochromocytoma: from genetics to personalized medicine. Nature reviews Endocrinology. 2015;11:101-111. 81. van Hulsteijn LT, Niemeijer ND, Dekkers OM, Corssmit EP. (131)I-MIBG therapy for malignant paraganglioma and phaeochromocytoma: systematic review and meta-analysis. Clinical endocrinology. 2014;80:487-501.

82. Carrasquillo JA, Pandit-Taskar N, Chen CC. I-131 Metaiodobenzylguanidine Therapy of Pheochromocytoma and Paraganglioma. Semin Nucl Med. 2016;46:203-214.

83. Puranik AD, Kulkarni HR, Singh A, Baum RP. Peptide receptor radionuclide therapy with (90)Y/ (177)Lu-labelled peptides for inoperable head and neck paragangliomas (glomus tumours). European journal of nuclear medicine and molecular imaging. 2015;42:1223-1230.

84. Delpassand ES, Samarghandi A, Zamanian S, et al. Peptide receptor radionuclide therapy with 177Lu-DOTATATE for patients with somatostatin receptor-expressing neuroendocrine tumors: the first US phase 2 experience. Pancreas. 2014;43:518-525. 85. Pinato DJ, Black JR, Ramaswami R, Tan TM, Adjogatse D, Sharma R. Peptide receptor radionuclide therapy for metastatic paragangliomas. Med Oncol. 2016;33:47.

86. Zovato S, Kumanova A, Dematte S, et al. Peptide receptor radionuclide therapy (PRRT) with 177Lu-DOTATATE in individuals with neck or mediastinal paraganglioma (PGL). Hormone and metabolic research $=$ Hormon - und Stoffwechselforschung $=$ Hormones et metabolisme. 2012;44:411-414.

87. Strosberg JR, Wolin E, Chasen B, et al. NETTER-1 Phase III in Patients with Midgut Neuroendocrine Tumors Treated with 177Lu-Dotatate: Efficacy and Safety Results. Journal of Nuclear Medicine. 2016;57:629.

88. Galan SR, Kann PH. Genetics and molecular pathogenesis of pheochromocytoma and paraganglioma. Clinical endocrinology. 2013;78:165-175.

89. Jafri M, Maher ER. The genetics of phaeochromocytoma: using clinical features to guide genetic testing. European journal of endocrinology / European Federation of Endocrine Societies. 2012;166:151-158.

90. Karasek D, Shah U, Frysak Z, Stratakis C, Pacak K. An update on the genetics of pheochromocytoma. Journal of human hypertension. 2013;27:141-147. 